\title{
EL CUERPO HUMANO Y EL DISPOSITIVO EXPEDICIÓN- CONQUISTA: UN EFECTO DE PRÁCTICAS HETEROGÉNEAS ${ }^{1}$
}

The human body and the expedition-conquest device: an effect of heterogeneous practices

Daniel Toscano López*

\section{Resumen}

En este artículo propongo una lectura del cuerpo humano como "efecto" de heterogéneas y múltiples prácticas, como la escribanía, la catequesis, la violencia física, el "mito literario" del conquistador y el "mito del fin de las antiguas culturas". Planteo que dichas prácticas están articuladas con lo que he llamado "dispositivo expedición-conquista", cuyo papel más importante es el de configurar las representaciones antagónicas del cuerpo entre el conquistador y el indígena en la conquista, de modo particular en México, en tiempos de Hernán Cortés y Moctezuma.

Palabras clave: Cuerpo humano, dispositivo, conquista, prácticas, efecto.

\section{Abstract}

In this article I propose a reading of the body as "effect" of heterogeneous and multiple practices, such as the clerkship, catechesis, physical violence, "literary myth" of the conqueror and the "myth of the end of the ancient cultures". I argue that such practices are articulated with what I have called "expedition-conquest device" which plays the role of the antagonistic set representations of the body between the conqueror and the conquered indigenous in a particular way in Mexico, in times of Hernán Cortés and Moctezuma.

Key words: Human body, device, conquest, practices and effects.

\section{DISPOSITIVO Y CUERPO HUMANO}

La importancia de pensar el cuerpo humano y ponerlo como centro de reflexión radica en que, como lo expresa Michel Serres: "el cuerpo carece de totalidad o unidad sintética, pero no por ello carece de principio ontológico, lógico y genealógico" (15). Si seguimos la cita anterior, que el cuerpo comporta un principio ontológico, ello supone que, lejos de ser una entidad maciza o realidad físico-material, este es, como lo expresa Merleau-Ponty, un "ser de dos hojas", porque pertenece al mundo de las cosas y porque comporta una "ambigüedad" o "reversibilidad". "Ambigüedad" es utilizado en la Fenomenología de la Percepción por el filósofo francés para atribuirlo al doble sentido del cuerpo, tanto corporal (Körper) como vivido (Leib). El cuerpo vivido "trasciende" al cuerpo físico o "cadavérico" dotándole de significado a la existencia, es decir, que no se agota en lo biológico pero siempre permanece enraizado en él. En palabras de Merleau

\footnotetext{
${ }^{1}$ Una primera versión de este artículo se expuso en el marco del Primer Encuentro Latinoamericano de Investigadores del Cuerpo en la Universidad de Rosario en Argentina, del 1 al 3 de agosto de 2012.
} 
Ponty: "la experiencia del propio cuerpo nos revela, por el contrario, un modo de existencia más ambiguo" (Fenomenología, 215). En el texto Lo visible y lo invisible este autor bautiza a este movimiento del cuerpo con el nombre de "réversibilité", "reversibilidad entre el vidente y lo visible, el tangente y lo tocado" (171). En la línea de situar el cuerpo desde la óptica de una fenomenología ontológica, es un autor como Hans Jonas quien lo aborda como condición de inteligibilidad del viviente, pues para él "el cuerpo vivo es el prototipo de lo concreto y, en la medida en que es mi cuerpo, es en su inmediatez simultánea de interioridad y exterioridad la única cosa concreta que se me da íntegra en la experiencia" (40).

Por otra parte, el cuerpo interpretado desde una perspectiva "tecno-lógica" dice relación con el hecho de pensarlo sobre la base de las condiciones biotecnológicas del mundo actual que lo moldean a partir del proceso de tecnificación de la vida misma, pues la técnica está enquistada en nuestros cuerpos. En efecto, el cuerpo, tal y como lo pone de relieve Donna Haraway, al estar inscrito dentro de códigos socioculturales, crea la imagen de un ser humano de seres encarnados en mundos de alta tecnología, esto es de cyborg, en tanto "creaturas de la realidad social", o "híbridos entre máquina y organismo" (7-45). Esta autora aborda el cuerpo desde una perspectiva "semióticomaterial", es decir, desde su transformación técnica toda vez que para ella "los cuerpos son mapas de poder e identidad y los cyborg no son una excepción (...) la máquina somos nosotros; las máquinas no nos dominan o amenazan" (38). En este orden de ideas, el filósofo italiano Roberto Esposito dirá que mientras Foucault enfatiza en el cuerpo normalizado y medicalizado, visto aún bajo la lógica de cierta unidad, Haraway "toma el cuerpo por el flanco de su descomposición y multiplicación merced al vertiginoso incremento de las nuevas tecnologías biónicas, electrónicas e informáticas" (206). Por su parte, en su concepción particular del cuerpo humano, Roberto Esposito hace hincapié en este como el "terreno más inmediato para la relación entre política y vida porque solo en aquel esta última parece protegida de lo que amenaza con corromperla o de su propia tendencia a sobrepasarse, a alterarse. Es como si la vida, para mantenerse como tal, tuviera que ser comprimida y custodiada en los confines del cuerpo" (26). Por tanto, para este autor el cuerpo es entendido no como una substancia o realidad maciza y cerrada de forma hermética, sino que "lejos de constituir un dato definitivo e inmodificable, es un constructo operativo abierto a un continuo intercambio con el ambiente circunstante" (30).

Por último, desde una perspectiva genealógica, como el mismo Foucault lo ha señalado en Vigilar y Castigar, el cuerpo del delincuente se disciplina para hacerlo dócil, se le retiene en el cuartel para domesticarlo y se le contiene en el aula de clases para que sea educado. De manera que si concebimos el cuerpo del ser humano como algo abierto y dinámico, y no como algo hermético y estático, estamos en condiciones de entender por qué razón se le explota en la fábrica para volverlo productivo, se lo modela físicamente para que se ajuste a algún canon estético, o, incluso, se gestionan sus afectos, deseos, memoria y atención. 
He querido ilustrar de manera breve mediante los anteriores ejemplos la validez de la afirmación de Michel Serres, según este, el cuerpo no "carece de principio ontológico, lógico y genealógico", de manera que retomo ahora la célebre y canónica distinción efectuada por Husserl entre, por una parte, cuerpo (Kö rper), esto es mera cosa física, biológica, mecánica, extensa o, incluso, cadavérica, $\mathrm{y}$, por otra, cuerpo vivo (Leib), pues es en esta segunda acepción que en este escrito abordo la idea de cuerpo humano. En palabras de este autor:

El cuerpo, por ende, se constituye primigeniamente de manera doble: por un lado es cosa física, MATERIA, tiene su extensión, a la cual ingresan sus propiedades reales, la coloración, la lisura, dureza, calor y cuantas otras propiedades materiales similares haya; por otro lado, encuentro en él, y SIENTO “en" él y "dentro" de él: el calor en el dorso de la mano, el frío en los pies, las sensaciones de toque en las puntas de los dedos (185).

Aludo a dicha distinción porque para los propósitos de la presente reflexión entenderé el cuerpo no como algo que se reduce a una esencia inmutable o sustancia homogénea como si se tratara de un dato familiar, dado de antemano e incontrovertible, sino como Leib o cuerpo vivo que se relaciona dinámicamente con el marco históricocultural, así como con las prácticas en las que se inscribe.

Para llevar a buen término lo anterior, primero preciso qué entiendo por el concepto de dispositivo poniendo de relieve su relación con el cuerpo humano con el fin de afirmar que este último es el resultado de prácticas históricas concretas que actúan como vectores o elementos constitutivos de lo que he dado en llamar "dispositivo expedición-conquista". En un segundo momento, como el nervio que sustenta esta reflexión consiste en presentar al cuerpo humano como el "efecto" de heterogéneas y múltiples prácticas, paso a demostrar de qué manera el "dispositivo expediciónconquista" ensambla en su seno prácticas como la escribanía, la catequesis, la violencia física, el mito literario del conquistador y el "mito del fin de las antiguas culturas" como es el caso de la cultura azteca. En último término, presento la invención-fabricación (Erfindung) del juego de representaciones del cuerpo entre conquistador e indígena en la conquista, de un modo particular en México, en tiempos de Hernán Cortés y Moctezuma.

Ahora bien, con miras a precisar lo que entenderé por "dispositivo expediciónconquista", no solo como categoría teórica, sino también como conjunto de prácticas que en su seno producen al cuerpo en términos de su representación, expondré tres perspectivas complementarias que trabajan la noción de "dispositivo" para extraer de ellas las notas características más importantes de la misma.

La primera acepción es la presentada por el filósofo Hubert Dreyfus y el antropólogo Paul Rabinow, para quienes, en sentido amplio, dicho término aglutina una variopinta cantidad de elementos, como por ejemplo: "discursos, instituciones, disposiciones arquitectónicas, reglas, leyes, medidas administrativas, enunciados científicos, proposiciones filosóficas, la moralidad, la filantropía, etcétera" (150). 
Asimismo, pero en sentido estricto, y siguiendo a Michel Foucault la palabra francesa dispositif (dispositivo) ha sido empleada por estos autores como "aparato" o "grilla de inteligibilidad". Una segunda perspectiva que no riñe con las anteriores, sino que la complementa, es la esbozada por Guilles Deleuze, para quien el dispositivo es una "máquina", "ovillo" o "madeja". Este autor, refiriéndose a las notas características del dispositivo como un "ovillo", establece que ellas "tienen, pues, como componentes líneas de visibilidad, de enunciación, líneas de fuerza, líneas de objetivación, líneas de subjetivación, líneas de ruptura, de fisura, de fractura que se entrecruzan y se mezclan mientras unas suscitan otras mediante variaciones o hasta de mutaciones de disposición" (157-158). En tercer lugar, el pensador italiano Giorgio Agamben al enfatizar en la función del dispositivo señala que este expresa: "una suerte -digamosde formación, que en un momento dado ha tenido la función de responder a una urgencia. El dispositivo tiene, entonces, una función estratégica dominante" (9). Este filósofo también esboza tres significados del término: jurídico, tecnológico y militar.

Lo importante a subrayar es que en estas tres acepciones, las cuales no riñen entre sí, existe una orientación hacia un mismo común denominador, de tal manera que entiendo por "dispositivo expedición- conquista":

1. Una "máquina" o "aparato" (Dreyfus y Rabinow) que "hace ver" y "hace hablar" la realidad misma, en este caso, al cuerpo o, mejor aún, su representación. No se trata de una unidad homogénea y maciza sino que, como lo conciben Foucault, Dreyfus y Rabinow, comporta una heterogeneidad de elementos que para nuestro caso se trata del ejercicio y práctica de la escribanía, la catequesis, la violencia física, el "mito literario del conquistador" y el "mito del fin de las antiguas culturas".

2. Un "ovillo" o "madeja" (Deleuze) que actúa como una "caja de resonancia" que, aunque articula una heterogeneidad de elementos, no obstante es particular y concreto. Si bien Foucault concibe al dispositivo como un "operador práctico", es decir que al inscribirse en relaciones de poder "tiene por función readecuar las relaciones de poder en un momento dado conforme a nuevos objetivos y siguiendo nuevas estrategias", no me ocuparé solo de las relaciones de dominación y poder dadas entre conquistadores e indígenas, lo que es evidente, sino que me referiré al papel del "dispositivo expedición-conquista" como un caleidoscopio que recoge heterogéneos vectores que configuran la representación o representaciones antagónicas del cuerpo.

3. Un dispositivo que entraña una función estratégica (Agamben), y que en el contexto a trabajar adopta varias aristas: la conquista es una gesta de interés económico que busca la riqueza que pretende beneficiar a la Corona, así como a oficiales de contaduría, cronistas y numerosos escribanos que se emplean en la Casa de Contratación de Sevilla adonde los tesoros van a parar, así como a quienes de manera directa participan de la expedición como los gobernadores, curas, conquistadores y soldados. Naturalmente que la conquista como "dispositivo" que hará que los cuerpos de los españoles y los de los indígenas sean representados de 
determinada manera tiene una función catequética y evangelizadora, además de estar motivada por el espíritu caballeresco de la época. Animados por la fe religiosa, movidos por la codicia y conducidos por un repertorio de leyendas, los españoles pretenden salvar al hereje de las llamas del infierno, buscan el palacio de malaquita del Gran Kan, así como los tesoros de Ofir.

4. Por último, el "dispositivo expedición-conquista" no es un mero conjunto de prácticas histórico-culturales abstractas e indeterminadas, sino que está inscrito, para nuestro caso, en el contexto específico de los comienzos de la conquista de México.

Mediante la expresión "dispositivo expedición-conquista" hago referencia al "mecanismo" conformado por heterogéneas prácticas histórico-culturales como la escribanía, la catequesis, la violencia física, el "mito literario" del conquistador y el "mito del fin de las antiguas culturas" que hacen posible que el cuerpo comporte distintas representaciones dentro de los comienzos de la conquista de México. En este sentido, la representación del cuerpo del conquistador y del conquistado está mediada históricamente por el choque de dos culturas, de visiones de mundo en conflicto y de cuerpos en tanto fuerzas contrapuestas en pugna y en vías de diferenciación, esto es de autoafirmación de su propia identidad. Por tanto, el cuerpo avasallado, enfermo, atravesado por flechas, sacrificado, fatigado, lejos de ser una unidad sintética o una totalidad hermética está constituido por un campo de tensión de prácticas culturales e históricas. Lo que quiero plantear es que el cuerpo humano es el "efecto" de un dispositivo que no es una invariable antropológica ni es agenciado de manera premeditada por sujetos que estén detrás de ellos para manipularlos, antes bien están inscritos en coordenadas históricas y contribuyen en la configuración del cuerpo humano, de manera que, en palabras de Michel Serres: "mi cuerpo y nuestra especie existen menos en lo real concreto que 'en potencia' o virtualidad" (64). Antes que una realidad a priori, estática, hermética y pasiva, el cuerpo es cambiante, abierto al mundo y activo. De allí que el riesgo de poner al cuerpo como centro de reflexión, sin atender a los procesos biológicos, históricos, políticos, sociales y culturales que lo constituyen, estriba en que se le termina cosificando y reduciendo a su imagen más inmediata.

\section{DISPOSITIVO EXPEDICIÓN-CONQUISTA}

A continuación abordo el "dispositivo expedición-conquista" como "máquina" que articula en su seno heterogéneas prácticas burocráticas administrativas españolas como las de la escribanía, la designación de alcaldes, regidores, maestre de campo, alguacil mayor y tesorero, pero también histórico-culturales como el "mito literario" por parte del español y el mito de Quetzalcóatl en los indígenas. Por práctica he de entender aquello que los hombres realmente hacen cuando hablan o cuando actúan. Estas entrañan un sentido que es inmanente, porque no remiten a algo fuera de ellas que las explica, siempre están en acto y no son engañosas. Asimismo, las prácticas, al estar en red, forman parte de un ensamblaje que en este caso es el llamado "dispositivo 
expedición-conquista", pero que, en ningún caso, no es la mera suma de las prácticas singulares y heterogéneas que lo conforman sino que funciona mediante reglas. Así, "los conjuntos prácticos" o "regímenes de prácticas" tienen una racionalidad. Las reglas, aunque no son visibles están presentes cuando decimos lo que decimos y hacemos lo que hacemos. Ahora bien, por práctica también entiendo lo que Habermas subraya en el texto Discurso filosófico de la modernidad, al referirse a Foucault: "regulaciones de las formas de acción, y costumbres consolidadas institucionalmente, condensadas ritualmente, y a menudo materializadas en formas arquitectónicas" (291).

El "dispositivo expedición-conquista" comporta al menos cinco prácticas: la escribanía, la catequización, la violencia física, el "mito literario" o la influencia de los libros de caballería en la gesta de la conquista y el "mito del fin de la civilización" de los aztecas. Las dos primeras, escribanía y catequización operan, por una parte, bajo la lógica de la legalidad-diplomacia y, por otra, la de la fe y la necesidad de la salvación del infiel. De este modo, la escribanía y la catequesis se erigen en "líneas de enunciación ${ }^{2}$ y visibilidad respectivamente". Por su parte, la violencia física, al alero de la lógica del dominio y de la codicia, opera como "línea de fuerza" del "dispositivo expedición-conquista", mientras que el "mito literario" y el del "fin de las antiguas civilizaciones" operan bajo la lógica de la ficción como "líneas de subjetivaciónobjetivación". No pretendo aquí precisar en qué sentido y cuáles prácticas se articulan, encabalgan, chocan, desplazan o complementan unas con otras, sin embargo, a continuación iré desgranando cada una de las cinco prácticas esbozadas.

Respecto de la escribanía y la catequesis, ambas funcionan reforzándose mutuamente a la manera de líneas de enunciación y visibilidad del "dispositivo expedición-conquista". Ahora bien, dentro del contexto de la conquista de México iniciada hacia 1517 por Francisco Fernández de Córdoba, retomada por Juan de Grijalba en 1518 y consolidada por Hernán Cortés a partir de 1519, la práctica de la escribanía funciona consignando los hechos al modo de una especie de ejercicio "notarial" de la realidad. Fernando Benítez, refiriéndose a la fundación de la ciudad de Veracruz en 1519, puerta estrecha de México, lo describe así: "entonces le toca intervenir al escribano Diego de Godoy. Su pluma de ave corre ligera por el grueso papel amarillento. Ese día memorable, queda fundada en nombre de los muy poderosos, excelentísimos, muy católicos y muy grandes reyes y señores doña Juana y el emperador Carlos V, su hijo, la Villa Rica de la Vera Cruz" (146). De este modo, junto

\footnotetext{
${ }^{2}$ También se ocupan expresiones como "régimen de verdad" y "estilo de pensamiento". Esta última es una expresión, acuñada por Ludwig Fleck, y definida por Francisco Vázquez García "para designar un nivel enunciativo que, a diferencia de lo que sugiere la noción kuhniana de "paradigma" es previo y condición de posibilidad para la formulación de proposiciones verdaderas o falsas". En Vásquez García, Francisco, "La medicalización y su sombra". Biopolíticas de la identidad sexual (España 1870-2007). Cortesía del autor. Una primera versión de este artículo fue presentada el 5/09/2013 en el IV Coloquio Latinoamericano de Biopolítica y II Coloquio Internacional de Biopolítica y Educación. Bienes comunes, tecnologías de gobierno, contra-conductas, celebrado en Bogotá del 3 al 6 se septiembre de 2013.
} 
con la escribanía se ejerce también el derecho a tomar posesión de tierras y personas en nombre del rey como una práctica recurrente cuando, por ejemplo, los españoles llegan a Tabasco o a Tenochtitlán al mando de Hernán Cortés.

Considero la práctica de la escribanía, la que está animada por la lógica de la legalidad-diplomacia, como línea de enunciación, pues por medio de ella no solo se establecen una jerarquía y unos roles cuando Cortés designa como acaldes de Veracruz a Puertocarrero y a Montejo, partidario de Diego Velázquez, sino que también se enuncia qué ciudad se funda, qué eventos son válidos y cuáles no, qué actos son legítimos y cuáles no. No es mi interés aquí discutir si la enunciación solo es descripción de acciones o si, por el contrario, la realiza. Lo enunciativo actúa en conjunción con líneas de fuerza, visibilidad, subjetivación y objetivación, lo que produce el cuerpo avasallado, propiedad, cosificado del indio o el cuerpo de los teules blancos, pero a veces enfermos, atravesados por flechas de los conquistadores.

"Lo legal", a su vez, da fuerza a la escribanía trazando la distinción entre el cuerpo-civilizado y el cuerpo-esclavo, el cuerpo que conquista y el cuerpo conquistado, el cuerpo que toma posesión y los cuerpos convertidos en cosa-propiedad. Fernando Benítez, refiriéndose a la poca importancia que tenían los indios para los españoles, dice que "eran simples bienes mostrencos, que pasaban a ser una pertenencia del primero que apareciera entre ellos enarbolando una espada y profiriendo extrañas fórmulas de posesión en un lenguaje desconocido" (55). En la primera de Las Cartas de relación de Cortés, la entrada de los españoles a un pueblo y la legalidad de dicho acto mediante la escribanía, son descritas del modo siguiente:

Y el dicho capitán Fernando Cortés se embarcó con hasta ochenta hombres en las barcas y bergantines, y se fue a poner frontero del pueblo para saltar en tierra si le dejasen; y como llegó halló los indios puestos de guerra armados con sus arcos y flechas y lanzas y rodelas, diciéndonos que nos fuésemos de su tierra, sino queríamos guerra que comenzásemos luego, porque ellos eran hombres para defender el pueblo. Y después de haber requerido el dicho capitán tres veces, y pedídolo por testimonio al escribano de vuestras reales altezas que consigo llevaba, diciéndoles que no quería guerra, viendo que la determinada voluntad de los dichos indios era resistirle que no saltase en tierra, y que comenzaban a flechar contra nosotros, mandó soltar los tiros de artillería que llevaba, y que arremetiésemos a ellos (12).

Las Cartas de relación escritas y enviadas, entre 1519 y 1526 por Hernán Cortés a la reina doña Juana y al emperador Carlos $\mathrm{V}$, su hijo, se erigen en una de las piezas del mecanismo complejo que instituye el "dispositivo expedición-conquista". Las cinco Cartas operan a manera de "líneas de visibilidad", que al revestir la forma de un relato describen y "dejan ver" y "hacen ver" las intenciones que animan los viajes de los españoles desde la "isla Fernandina" o actual Cuba hacia lo que después será conocido como México y será denominado en ese tiempo "Nueva España". El poder del soberano se hace sentir en el cumplimiento de órdenes de Cortés en la medida en que la 
vida está por completo en manos del soberano, quien la concede o quita, el soberano tiene el poder de apropiarse de las fuerzas vitales del súbdito y emplearlas como quiera, guerra, labores agrícolas o esclavitud. La diana del poder soberano es el territorio y sus habitantes. Es una visibilidad del orden de la verticalidad, propia del poder soberano, de arriba abajo y en donde la producción de verdad se condensa en las prácticas de escribanía y la catequesis.

Quiero subrayar que aquello que he dado en llamar "dispositivo expediciónconquista" no toma como blanco directo el cuerpo mismo, sino que, antes bien, el objetivo es corregido y calibrado estratégicamente, ya que en un comienzo es la esclavitud o la mano de obra requerida para la isla de Cuba, pero luego ese objetivo se yuxtapone al del "rescate" de oro cuando desde la primera expedición Francisco Fernández de Córdoba lo manifiesta al gobernador de Cuba, después de recibir varias heridas: "se volvió con los dichos navíos y gente a la isla Fernandina donde hicieron saber al dicho Diego Velázquez como habían hallado una tierra muy rica de oro, porque a todos los naturales de ella los habían visto traer puesto adellos en las narices, adellos en las orejas y en otras partes" (Cortés, 6). Además de que la expedición-conquista fuera animada por el requerimiento de cuerpos y mano de obra para la isla de Cuba, del rescate del oro, también es clara la intención de "catequizarlos" y convertirlos en vasallos de la Corona. Estas dos últimas ideas se ponen de relieve así:

Y el dicho Fernando Cortés hablándoles por medio de una lengua o faraute que llevaba, les dijo que no iban a hacerles mal ni daño alguno, sino para les amonestar y atraer para que viniesen en conocimiento de nuestra santa fe católica y para que fuesen vasallos de vuestras majestades y les sirviesen y obedeciesen como lo hacen todos los indios y gentes de estas partes que están pobladas de españoles, vasallos de vuestras reales altezas (Cortés, 9).

En el caso de Cortés y su tropa, el objetivo parece ser el de servir a Dios y a su majestad con el propósito de aumentar sus señoríos, multiplicar las rentas y, por último, poblar las tierras conquistadas. Recordemos que por "derecho real" a la Corona le pertenecía la quinta parte de lo "rescatado" en las tierras conquistadas. Al mismo tiempo esa era la manera en la que el conquistador y los soldados servían a Dios y a la majestad. A cambio, por medio de cabildos y por acuerdo entre los mismos conquistadores, elegían sus procuradores con el fin de mantener la pacificación, la concordia y, en último término, velar por el bien público,

En relación con la práctica de la "catequesis", los españoles tienen la misión de instruir a los indios en los misterios de la fe católica. A tal práctica subyace la lógica de la conversión, pues Cortés señala en la Primera relación que ha visto cómo en los templos, los que son confundidos con "mezquitas", se quema incienso y se sacrifican personas, además, "cortándose unos las lenguas y otros las orejas, y otros acuchillándose el cuerpo con unas navajas" (17). Ante la costumbre del sacrificio de los cuerpos de mujeres, niños y ancianos, Cortés y los demás conquistadores no reparaban en librar a los indios de dicho mal, reprendiéndoles de la idolatría de los dioses, 
entregándoles cruces de madera e imágenes de la virgen María. El resultado es que con ello los españoles ven al indio como gente bárbara, pero que si se les hace entender la verdad de la fe podrían apartarse del error en que estaban. La "línea de visibilidad" de la catequesis produce un nuevo repertorio de creencias, costumbres y símbolos a los que cuerpos obedientes, sumisos, servidores y pecadores deben enderezarse. Así, por ejemplo, en uno de los primeros pueblos en obedecer a la Corona, "cinco días permanecen los españoles en Tabasco, al que bautizan como Santa María de la Victoria, entregados a pláticas con los caciques, con el fin de ganar sus almas para el cielo, y sus cuerpos pecadores para la mayor gloria del Emperador Carlos V" (Benítez, 112). Es allí en Tabasco en donde también los españoles reciben veinte mujeres como "regalo" de los Caciques, en lo que podríamos denominar un anticipo del cuerpo-mercancía, pues "cada una de ellas pertenece un dios blanco, al que han de servir en lo que mande" (Benítez, 115).

La violencia física, en tanto "línea de fuerza" del "dispositivo expediciónconquista" parece comenzar a practicarse allí donde la legalidad y la diplomacia de la escribanía se agotan; sin embargo, legalidad y belicosidad se encabalgan bajo la lógica del dominio que esta última comporta. La práctica de la guerra o violencia física es orientada por un código de caballería que hace del conquistador un cuerpo animado por el espíritu caballeresco que pueda mostrar su arrojo en el combate. De esa forma "las armas son su única profesión y su sola esperanza de glorias y de riquezas en aquella cruzada enderezada contra pueblos gentiles" (Benítez, 107). En los primeros atisbos, los Tabasqueños cuando ven entrar en acción los trece caballos de Cortés "se imaginan que caballo y caballero forman un solo monstruo ser animado de mágicos poderes" (Benítez, 109). La práctica de la guerra expone a los cuerpos tanto del indio como del conquistador adoptando variadas representaciones y formas como cuerpos muertos, agonizantes, fatigados, sudorosos y enfermos, triunfantes y derrotados. En la ruta que iba desde Veracruz a Tenochtitlán, y luego de tomar Cempoala y destruir sus ídolos sin dilación, Cortés se enfrenta a los Tlaxcaltecas. Es en la segunda Carta de relación en la que Cortés describe a Tlaxcala y la compara a la ciudad española de Granada, que él, de nuevo, manda llamar al escribano para que certifique que viene de paz, porque lo reciben los indios en actitud de guerra. Por tanto, en la confrontación violenta entre el conquistador y el indio se aúnan la codicia temporal, la necesidad de oro, riquezas, mujeres, y de indios que trabajen la tierra, así como la necesidad de grandeza y poder.

Por su parte, el "mito literario" del conquistador y el "mito del fin" de las grandes culturas como el de Quetzalcóatl en tanto "líneas de objetivación y subjetivación" del "dispositivo expedición-conquista" contribuyen a fraguar también distintas representaciones del cuerpo. Es a partir del año 1500 que proliferan los libros de caballería fundiendo la verdad con la ficción, instan al conquistador a que se lance en aventuras fantásticas en pos de islas exóticas, seres extraños y tesoros ocultos. Los libros de caballería producen un gran efecto en la imaginación del conquistador: libros como Tirant lo Blanch (Tirante el Blanco) en 1490; Amadís de Gaula en 1508; Sergas de 


\section{Daniel Toscano López}

Esplandián, en 1510, en el que aparecen el mito de las amazonas; Florisando, en 1510; Palmerín de Oliva, en 1511; Caballero Cifar, en 1512; Lisuarte de Grecia, en 1514; Amadis de Grecia, en 1530; Don Florisel de Niquea, en 1532. Acerca del efecto de los libros de caballería en los conquistadores, Leonard Irving sostiene que:

Si entre los intelectuales este efecto se limitaba de modo principal a sus propias expresiones literarias, producíase en cambio más profundamente sobre la mayoría de los menos cultos, modificando sus hábitos y costumbres, y muchos de los hombres rudos que constituyeron el grueso de las huestes conquistadoras, se lanzaron a la aventura en tierras lejanas por lo que les había enseñado a soñar la literatura caballeresca. Al mando de capitanes tan intrépidos como Cortés, Pizarro y Jiménez de Quesada, hicieron prodigios de auténtico valor, que con su audacia y su heroísmo empequeñecieron el mundo imaginario de Amadís y de los demás caballeros andantes" (40).

Previo a la conquista de los españoles y portugueses a América es evidente que no existía una referencia clara del cuerpo de unos y otros. Asimismo, aun lo que las crónicas mismas narran están lejos de aglutinar un tratado acerca de la concepción del cuerpo que imperaba en ese momento. Si bien es un lugar común decir que el conquistador en su primer viaje al llegar a América no contaba de manera deliberada con llegar a estas tierras; sin embargo, mediante libros de caballería en boga y de mitos literarios como el de las Amazonas tenía arraigada la creencia de que más allá del viejo mundo podrían existir seres como los de aquellos relatos. Un gran repertorio de leyendas e imágenes circula por Europa antes de que Colón creyera alcanzar el oriente por el poniente. En palabras de Fernando Benítez:

Sí, colón hace suyas todas y cada una de las fantasías europeas. Tiene la cabeza llena de gigantes y enanos, de hombres con rabo y de seres que andan sobre un pie, tienen un ojo y son peludos como demonios (...) De su imaginación no se apartan la isla Trepobana y la de Cipango, donde hay perlas y montañas de oro guardadas por dragones y unicornios (34).

Las lecturas de libros de caballería como prácticas que operan como líneas de "objetivación-subjetivación" operan dotando de realismo a los míticos caballeros que contaban las gestas de los libros. Objetivación, por cuanto la aparente historicidad de los relatos y los nuevos hallazgos con que el español se encontraba al expandir su horizonte físico hacían verosímiles las ficciones leídas. Bernal Díaz del Castillo, cronista que figuraba en el ejército de Cortés, describe así la primera impresión entre los españoles la vista de la capital azteca:

$\mathrm{Y}$ desde que vimos tantas ciudades y villas pobladas en el agua, y en tierra firme otras grandes poblazones, y aquella calzada tan derecha y por nivel como iba a México, nos quedamos admirados, y decíamos que parecía a las cosas de encantamiento que cuentan en el libro de Amadís, por las grandes torres o cúes y edificios que tenían dentro en el agua, y todas de calicanto, y aun alguno de nuestros soldados decían que si aquello que veían, si era entre sueños, y no es de 
maravillar que yo lo escriba aquí de esa manera, porque hay mucho que ponderar en ello (82).

Los relatos de rescates de doncellas, combates individuales y colectivos, monstruos, gigantes, amazonas, fuentes de la juventud, las siete Ciudades míticas, islas encantadas, el Dorado y seres extraordinarios motivaron a querer "palpar" en la realidad las maravillas, riquezas y aventuras allí contadas. Tal motivación se ve en la descripción que Cortés hace de los cuerpos de los indios de México:

La gente de esta tierra que habita desde la isla de Cozumel y punta de Yucatán hasta donde estamos es una gente de mediana estatura, de cuerpos y gestos bien proporcionada, excepto que en cada provincia se diferencian ellos mismos los gestos, unos horadándose las orejas y poniéndose en ellas muy grandes y feas cosas, y otros horadándose las ternillas de las narices hasta la boca y poniéndose en ellas unas ruedas de piedras muy grandes que parecen espejos, y otros se horadan los bezos de la parte de abajo hasta los dientes, y cuelgan de ellos unas grandes ruedas de piedra o de oro tan pesadas que les hacen traer los bezos caídos y parecen muy disformes" (16).

Por otra parte, la "ficción literaria" o los libros de caballería influyen sobre la mente y comportamiento del conquistador operando como "línea de subjetivación", por cuanto este se experimenta a sí mismo en la convicción de cumplir un destino como instrumento de Dios en la empresa de cristianizar a los indios y para ello su cuerpo valeroso es pieza fundamental en la conquista:

Valor individual frente a los mayores obstáculos, aceptación estoica de desventuras y heridas, exaltado sentido del honor y de la dignidad personal, maneras corteses y un concepto caballeresco del amor, todo esto reflejaba los más altos ideales del carácter español, forjado en un largo y triunfante batallar contra el extranjero infiel, invasor de la península (Irvine, 49).

Antes de la llegada de los conquistadores a tierras mexicanas, hubo presagios que los aztecas tomaron por señales que les anunciaban el fin de su cultura: un cometa, el agua de un lago que hierve sin que hubiera viento, el incendio sin causa del templo de Xiuhtecuhtli, el rugido de un volcán o la incesante amenaza de la naturaleza que lleva a que sus rituales incorporen al cuerpo dentro del sacrifico a los dioses. Esta "línea de objetivación" en cuanto genera una cosmovisión de la realidad en donde los dioses les castigan es también línea de subjetividad del "dispositivo expedición-conquista", por cuanto lo que parece tener mayor poder sobre la acción del indio es la imagen del mito acerca de su pensamiento y del cumplimiento del fin de su cultura incorporado en su cosmogonía.

Es Quetzalcóatl, uno de los grandes dioses del panteón azteca, quien dio la vida al hombre en su última generación el que volverá de oriente, pues "dioses adversos y engaños de nigrománticos le obligaron a emprender la huida hacia un país, más allá del mar, que el mito denomina Tlallapan" (Salas, 108). Es por esto que los aztecas no precisan saber si los dioses habitan la piel de esos teules blancos venidos de oriente, que 
vienen en templos flotantes, junto con el poder de sus armas, el sonido del arcabuz, la explosión de la lombarda son el modo en que el poder de lo sagrado se manifiesta. Cortés navega con once navíos el 10 de febrero de 1519 rumbo a la isla de Cozumel, frente a Yucatán. Va con quinientos ocho soldados, dieciséis caballos, diez cañones de bronce y cuatro falconetes. Marta Dujovne según las ilustraciones del Códice Florentino, el que articula la tradición indígena de la imagen como escritura con la imagen como ilustración de la cultura europea, señala que "cuando los españoles entraron en la ciudad Moctezuma se adelantó a recibirlos con todos los honores, pensando que quizás se tratara del "regreso de los dioses' tan largamente esperado" (63).

Las prácticas de la escribanía, la catequesis, la violencia física, el "mito literario" alimentado por los libros de caballería y el "mito de Quetzalcóatl" son heterogéneas líneas que se ensamblan en lo que he denominado "dispositivo expedición-conquista", el que forma un caleidoscopio que genera representaciones múltiples del cuerpo como el cuerpo-posesión o cuerpo-cosa, el cuerpo atravesado por flechas o el cuerpo enfermo, el cuerpo de los dioses blancos, el cuerpo del indio infiel y no civilizado. Dichas prácticas terminan por invisibilizarse o, mejor aún, naturalizarse, de tal modo que al asumir el papel de lo más cercano, familiar y evidente, paradójicamente, terminan por erigirse en una especie de "parte oculta de un iceberg" que es ignorada cuando la vista se fija en la parte emergente. Ese ocultamiento de las prácticas, al decir de Dreyfus y Rabinow se explica porque en relación con el hombre: "este no puede reflexionar sobre qué son las prácticas, precisamente porque están demasiado cerca de él y, por eso, son demasiado abarcadoras" (65). Este punto de naturalización-invisibilizacón de las prácticas es importante porque estas coadyuvan a formar diversas representaciones del cuerpo. De este modo, el cuerpo en tanto representación es un efecto u objetivación de las prácticas; no obstante, tal representación del cuerpo termina por sedimentarse, cristalizarse o naturalizarse. Por eso el cuerpo no es un objeto en sí mismo, sino un "campo" de acción generado a partir de un conjunto de prácticas heterogéneas.

\author{
Universidad La Gran Colombia* \\ Facultad de Educación \\ Grupo de Investigación Educación y Pedagogía \\ Cra. 6 No. 12-40, Bogotá (Colombia) \\ daniel.toscano@ugc.edu.co
}

\title{
OBRAS CITADAS
}

Agamben, G. Qu'est-ce qu'un dispositif? Paris: Éditions Payot \& Rivages, 2007.

Benítez, F. La ruta de Hernán Cortés. México: Fondo de Cultura Económica, 1950.

Cortés, H. Cartas de relación. Segunda edición, México, D.F.: Porrúa, 1963.

Deleuze, G. “¿Qué es un dispositivo?” en Balbier, Deleuze, Dreyfus et al., Michel Foucault, filósofo. Barcelona: Gedisa, 1990. 
Díaz del Castillo, B. Verdadera Historia de la Conquista de la Nueva España, cap. LXXXVII (en Enrique de Vedia, Historiadores primitivos de Indias, II. Biblioteca de Autores Españoles, vol. 26).

Dreyfus H. y Rabinow, P. Michel Foucault: más allá del estructuralismo y la hermenéutica. Buenos Aires: Nueva visión, 2001.

Dujovne, M. La conquista de México. México, D. F.: Nueva imagen, 1978.

Esposito, Roberto, Immunitas: protección y negación de la vida. Trad. Luciano Padilla López, 1a. edición. Buenos Aires: Amorrortu, 2005.

Habermas, J. El discurso filosófico de la Modernidad, Madrid: Taurus, 1989.

Haraway, Donna, "A Manifesto for Ciborgs: Science, Technology, and Socialist Feminism in the 1980s", en The Haraway Reader, London: Routledge New York and London, 2004: (7-45).

Husserl, Edmund, Ideas relativas a una fenomenología pura y una filosofia fenomenológica. Libro segundo: Investigaciones fenomenológicas sobre la constitución, Segunda edición en Castellano, traducción de Antonio Zirión Q. México, D. F.: Fondo de Cultura Económica, 2005.

Irving, L. Los libros del Conquistador. México, D.F.: Fondo de Cultura Económica, 1979.

Jonas, Hans, El principio vida, Trad. José Mardomingo, Madrid: Trotta, 2000.

Merleau-Ponty, Maurice. Le visible et l'invisible, Texte établi par Claude Lefort, Paris, Gallimard, 1964. [Versión en castellano: Lo visible y lo invisible. Trad. José Escudé, Barcelona: Seix Barral, 1970].

— Fenomenología de la percepción. Trad. Jem Cabanes, Barcelona: Planeta-De Agostini, 1985.

Salas, Alberto. Las armas de la Conquista. Buenos Aires: Emecé, 1950.

Serres, Michel. Variaciones sobre el cuerpo. Buenos Aires: Fondo de Cultura Económica, 2011.

Vásquez García, Francisco. "La medicalización y su sombra". Biopolíticas de la identidad sexual (España 1870-2007). Cortesía del autor. Una primera versión de este artículo fue presentada el 5/09/2013 en el IV Coloquio Latinoamericano de Biopolítica y II Coloquio Internacional de Biopolítica y Educación. Bienes comunes, tecnologías de gobierno, contra-conductas, celebrado en Bogotá del 3 al 6 se septiembre de 2013 . 